(c) American Dairy Science Association, 2004.

\title{
An Economic Spreadsheet Model to Determine Optimal Breeding and Replacement Decisions for Dairy Cattle
}

\author{
H. Groenendaal, ${ }^{1}$ D. T. Galligan, ${ }^{1}$ and H. A. Mulder ${ }^{2}$ \\ ${ }^{1}$ New Bolton Center, Center of Animal Health and Productivity School of Veterinary Medicine, \\ University of Pennsylvania, Kennett Square 19348 \\ ${ }^{2}$ Animal Breeding and Genetics Group, Wageningen University, The Netherlands
}

\section{ABSTRACT}

The aim of this paper is to describe a user-friendly spreadsheet culling model that was constructed to support economical, optimal breeding and replacement decisions on dairy farms. The model was based on the marginal net revenue technique. Inputs for the model can be entered for specific farm conditions, and the output is easily accessible. In the model, the retention pay-off (RPO) value of individual dairy cows was calculated. The RPO value of a cow is equal to the total additional profits that a producer can expect from trying to keep the cow until her optimal age, taking into account the changes of involuntary removal compared with her immediate replacement. To calculate the RPO values, the future production, revenues, and costs of dairy cows at different levels of milk production with different numbers of days open (DO) were determined. Furthermore, the ranges of carcass value, calf revenues, and the range of involuntary disposal rates of cows within and across lactations were taken into account. To illustrate the model, parameters in the model were chosen to represent a typical Holstein dairy herd in Pennsylvania. The results of this model are very comparable with earlier, more complex models that are more difficult to use on the farm. In addition to using the RPO values to evaluate the decision to breed or replace a cow, the costs per additional DO were estimated. Early conception was most profitable with the costs per additional DO varying from $\$ 0$ to more than $\$ 3 / \mathrm{d}$. The model can be used as a decision-supporting tool for producers, extension personnel, veterinarians, and consultants. In addition, researchers, economists, and government organizations can use the model to determine the costs of culling dairy cows in a disease control program. The model and manual are available at http:// cahpwww.vet.upenn.edu/software/econcow.html.

Received June 5, 2003.

Accepted February 12, 2004.

Corresponding author: H. Groenendaal; e-mail: huybert@risk -modelling.com.
(Key words: replacement, economic model, retention pay-off, cost per extra day open)

Abbreviation key: $\mathbf{C I}=$ calving interval, $\mathbf{D O}=$ days open, $\mathbf{D P}=$ dynamic programming, $\mathbf{M N R}=$ marginal net revenue, $\mathbf{R P O}=$ retention pay-off.

\section{INTRODUCTION}

An important goal of a commercial dairy farmer is maximization of total farm profits (Renkema and Stelwagen, 1979). Breeding and replacement decisions play an important role in the management of a dairy herd (Van Arendonk, 1985a; Jalvingh, 1993). Several studies found that the replacement policy of dairy cows greatly influences the profitability of the herd (Renkema and Stelwagen, 1979; Congleton and King, 1984). Thus, maximizing farm profits requires optimizing reproduction and replacement decisions (DeLorenzo et al., 1992).

On dairy farms, the most observed reasons for culling cows are reproductive problems, low production, and mastitis (Morris and Marsh, 1985; Van Arendonk, 1988). Although culling decisions are of great economic importance for a dairy farm, they are often made in a non-programmed fashion and based partly on the intuition of the decision-maker (Lehenbauer and Oltjen, 1998). To improve expected future profits on the dairy farm, culling decisions should be based on economic principles rather than on biological considerations (Dijkhuizen, 1983; Lehenbauer and Oltjen, 1998). Economic analysis of the replacement decision should include the expectation of the cow's future performance as well as that of the potential replacement (Dijkhuizen, 1983).

To evaluate decisions on dairy cattle breeding and replacement, 2 main techniques, marginal net revenue (MNR) and dynamic programming (DP), have been applied. Burt (1965) stated that the MNR approach is, in fact, a special case of DP. Both techniques rely on the production function approach in which the economic costs and revenues of a cow are modeled during her life span (Van Arendonk, 1985a). The 2 main differences between the MNR and the DP approach (and limitations of the MNR approach) are 1) the DP approach can 
take into account the variation in expected performances of both present and subsequent replacement, and 2) DP can take into account genetic improvement. Because DP can overcome both limitations of the MNR approach, many researchers (Giaever, 1966; Van Arendonk, 1985a, DeLorenzo et al., 1992; Jalvingh, 1993; Kristensen, 1993; Houben, 1995) have used DP techniques to provide guidelines for replacement and breeding decisions.

A problem with the DP technique, however, is that DP models can easily become very large and complicated depending on the number of states defined, incurring the risk of limited breadth of application because of intensive resources requirements (Smith et al., 1993). Although more efficient DP models have been developed (Kristensen, 1993), most of the DP models that have been developed so far are relatively complicated and need high computer skills to use. In addition, most DP models are compiled with many fixed parameters, thus limiting the number of parameters that could be changed by the user. Furthermore, most of the existing models are not very user friendly and have interfaces that are unfamiliar to the end users. The majority of effort on decision-supporting models in the dairy industry has been focused on constructing models (Van Arendonk, 1985a; Kristensen, 1993; Houben, 1995) rather than on using models as applied decision-making tools. This fact is illustrated by the observation that, to our knowledge, none of the existing models are directly available. As a consequence, little progress has been made at the farm level in making better culling decisions (Lehenbauer and Oltjen, 1998).

For use as a decision-supporting tool on the dairy farm, a model should be simplified as much as possible without compromising the accuracy of outputs. For that reason (Van Arendonk, 1985a) and for the possibility of structuring a replacement model in a spreadsheet program that is familiar and easily available to the end users, the MNR approach sometimes can be justified. An often-cited limitation of the MNR approach (Van Arendonk, 1985a; Kristensen, 1993) is its inability to easily account for genetic improvement. However, Van Arendonk (1985a) concluded that genetic improvement hardly affected the optimal breeding and replacement policy. A second limitation of the MNR approach is that it does not easily take into account the variation in the expected performance of present animals. However, as the expected performance of a replacement heifer, which is used in the MNR approach, is equal to the average of the probability distributions that are used in the DP model, both models are likely to give very similar results. In other words, although DP takes into account variation, the optimal decisions in both meth-

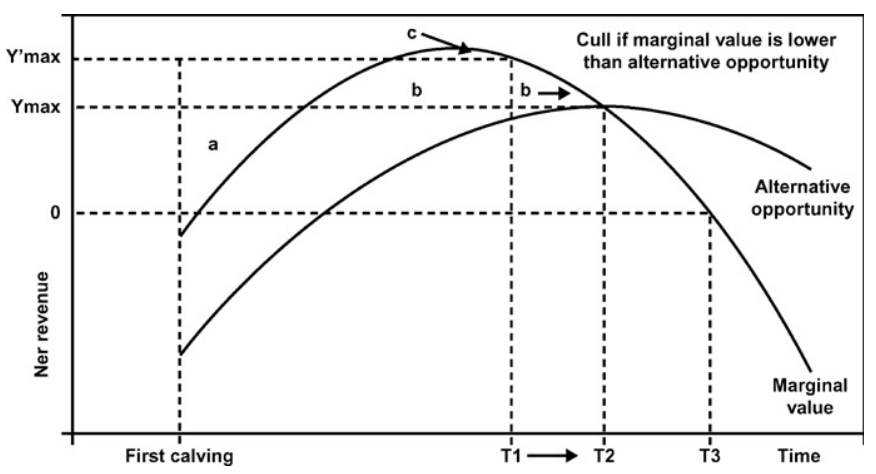

Figure 1. Graphical representation of the way to establish the optimal time for replacement in a situation without an alternative opportunity (T3) and in situations of identical replacement (T2) and non-identical (in this case better) replacement (T1) (modified from Huirne et al., 1997).

ods are based on the expected performances of the animals in the herd.

The goal of the current paper is to describe a spreadsheet dairy cattle replacement model. With the model, optimal replacement and breeding decisions can be supported for cows with different production characteristics. With the model, the costs per additional day open (DO) for cows with different production characteristics can also be calculated. The model is based on the MNR approach and is user friendly in that it allows users to easily change all input parameters under different production and economic situations on dairy farms.

\section{MATERIALS AND METHODS}

\section{Calculations}

The optimum time for replacement of a dairy cow was determined by comparison of the MNR anticipated from the present cow with the economic opportunity of a replacement. The latter value equals the maximal average discounted net revenue anticipated from replacement cows, also reported as annuities (Van Arendonk and Dijkhuizen, 1985; Brealey and Myers, 2000). Figure 1 shows a graphical representation of these calculations for 3 situations. For a situation with identical replacement (T2) or non-identical replacement (T1), the optimum time of replacement was defined as the first time period in which the annuity value of the cow drops below the maximal annuity value of the replacement animal. The maximal annuity calculation of the replacement was based on the average performance of animals present in the herd, assuming this to be the best estimate for expected future net revenue of young replacement animals. For the situation T2, the retention pay-off (RPO) value would be calculated as the 
area 'b' plus 'c' minus the area 'a,' all shown in Figure 1. For a situation without a replacement animal available (T3; no alternative opportunity), the optimal time of replacement is equal to the time period in which the MNR decreases below zero (Huirne et al., 1997). The $R P O$ value in this situation would be equal to the net area below the marginal value line.

All future revenues and costs were weighted with the probability of animal survival. Animal survival $\left(\mathrm{p}_{\mathrm{i}}\right)$ was defined as 1 , probability on involuntary culling. A formula, modified from Huirne et al. (1997), was used to calculate net revenues as an annuity per month (Brealey and Myers, 2000):

$$
\begin{aligned}
\mathrm{ANR}_{\mathrm{j}} & =\left[\Sigma_{\mathrm{i}=1 \ldots \mathrm{j}} \mathrm{p}_{\mathrm{i}} * 1 / 1(1+\mathrm{r})^{\mathrm{i}} * \mathrm{MNR}_{\mathrm{i}}\right] \\
& * \mathrm{r} /\left[1-(1+\mathrm{r})^{-\Sigma \mathrm{i}=1 \ldots \mathrm{j} \mathrm{pi} * \mathrm{mi}}\right]
\end{aligned}
$$

where

$$
\begin{aligned}
\mathrm{ANR}_{\mathrm{j}}= & \text { annuity of the net revenue of a replace- } \\
& \text { ment animal per month; } \\
\mathrm{i}= & \text { decision moment of replacement }(1 \leq \mathrm{I} \leq \\
& \mathrm{j} \text { ) at the end of period } \mathrm{i} ; \\
\mathrm{j}= & \text { period, at the end of which an animal can } \\
& \text { be replaced; } \\
\mathrm{r}= & \text { discount rate per month; } \\
\mathrm{p}_{\mathrm{i}}= & \text { probability of survival until the end of pe- } \\
& \text { riod } \mathrm{i} \text {, calculated from the moment at } \\
& \text { which a young animal starts its first pro- } \\
& \text { duction (end of period } 0) ; \\
\mathrm{m}_{\mathrm{i}}= & \text { length of period } \mathrm{i} \text { (mo); and } \\
\mathrm{MNR}_{\mathrm{i}}= & \text { MNR in period } \mathrm{i} \text {, including a change in } \\
& \text { slaughter value and financial loss associ- } \\
& \text { ated with involuntary disposal. }
\end{aligned}
$$

In the current application of the model in this paper, the replacement animal was assumed to have been bred to an average calving interval (CI) and kept until her maximal annuity value was reached.

The RPO value of a cow is equal to the total additional profits that a producer can expect from trying to keep the cow until her optimal age, taking into account the changes of involuntary premature removal compared with her immediate replacement (Huirne et al., 1997). In other words, the RPO value represents the maximum amount of money that could be spent to try to keep an animal in case of reproductive failure or health problems. The RPO value assumes that the only opportunity, other then keeping the cow, is a replacement heifer. Therefore, the maximization of net revenue per cow-place per year in the long run is the objective, and the opportunity costs have to be included in the calculation. The RPO value was calculated as follows (Huirne et al., 1997):

$$
\begin{gathered}
\mathrm{RPO}_{\mathrm{i}}=\sum_{\mathrm{j}=\mathrm{j}+1 . \mathrm{d}} * \mathrm{p}_{\mathrm{j}} * 1 /(1+\mathrm{r})^{\mathrm{j}} *\left(\mathrm{MNR}_{\mathrm{j}}\right. \\
\left.-\mathrm{ANR}_{\max } * \mathrm{~m}_{\mathrm{j}}\right)
\end{gathered}
$$

where

$$
\begin{aligned}
\mathrm{RPO}_{\mathrm{i}}= & \mathrm{RPO} \text { at decision moment } \mathrm{i} ; \\
\mathrm{d}= & \text { optimal moment for replacement (when } \\
& \left.\mathrm{MNR}_{\mathrm{j}}<\mathrm{ANR}_{\text {max }}\right) ; \\
\mathrm{r}= & \text { discount rate per month; } \\
\mathrm{p}_{\mathrm{j}}= & \text { probability of survival until the end of pe- } \\
& \text { riod } \mathrm{j}, \text { calculated from decision moment } \mathrm{i} ; \\
\mathrm{j}= & \text { period, at the end of which an animal can } \\
& \text { be replaced; } \\
\mathrm{m}_{\mathrm{j}}= & \text { length of period } \mathrm{j}(\mathrm{mo}) ; \\
\mathrm{MNR}_{\mathrm{j}}= & \text { MNR in period } \mathrm{j} ; \text { and } \\
\mathrm{ANR}_{\text {max }}= & \text { expected maximum average net revenue } \\
& \text { per month. }
\end{aligned}
$$

In the model, the RPO values can be calculated for different production levels, which were defined relative to the herd average milk yield. The herd average milk yield in this application was set at $9072 \mathrm{~kg}(20,000 \mathrm{lb}) /$ yr per cow. In the current model's application, the RPO values of 5 production levels $(76,88,100,112$, and $124 \%$ of average) were calculated, but any level can be used. To capture different reproductive efficiencies, the model calculates the RPO values for cows with CI of 11,12 , ...17 mo. The CI in the following lactations can take on a variety of levels, including the overall herd average (set as default). The herd average CI, without confounding by culling, was calculated by:

$$
\mathrm{CI}_{\text {aver. }}=\mathrm{RND}((\mathrm{VWP}+21 /(\mathrm{EDR} * \mathrm{CR})+\mathrm{LP}) / 30.4)
$$

where

$$
\begin{aligned}
\mathrm{CI}_{\text {aver. }}= & \text { average } \mathrm{CI}(\mathrm{mo}), \\
\mathrm{RND} & =\text { rounding function, } \\
\mathrm{VWP} & =\text { voluntary waiting period }(\mathrm{d}), \\
\mathrm{EDR}= & \text { estrus detection rate }(\%), \\
\mathrm{CR}= & \text { conception rate }(\%), \text { and } \\
\mathrm{LP}= & \text { length of pregnancy (assumed to be } \\
& 274 \mathrm{~d}) .
\end{aligned}
$$

In the current application, the average $\mathrm{CI}\left(\mathrm{CI}_{\text {aver. }}\right)$ was calculated at 15 mo (for input parameters, see Table 1). This average CI was used as the expected CI of replacement heifers.

After calculating the RPO values, the costs per DO were calculated by the model:

$$
\mathrm{CDO}_{\mathrm{CI}}=\left(\mathrm{RPO}_{\mathrm{CI}}-\mathrm{RPO}_{\mathrm{CI}+\mathrm{I}}\right) / 30.4
$$


Table 1. Parameter values used for variables in the example applications of the culling model for a typical dairy herd in Pennsylvania.

\begin{tabular}{|c|c|c|}
\hline & Variable $^{1}$ & $\begin{array}{l}\text { Parameter value, } \\
\text { price, or unit }\end{array}$ \\
\hline \multirow[t]{10}{*}{ Price } & Milk & $\$ 0.287 / \mathrm{kg}$ \\
\hline & Calf value & $\$ 100$ per calf \\
\hline & Cost of replacement heifer & $\$ 1132$ per heifer \\
\hline & Veterinary costs (for an average first-calving heifer) & $\$ 50 /$ yr per cow \\
\hline & Financial losses at disposal & $\$ 50$ per case \\
\hline & Insemination costs & $\$ 12$ per breeding \\
\hline & $\begin{array}{l}\text { Feed costs, lactation (feeding program based } \\
\text { on milk production) }\end{array}$ & $\$ 0.20 / \mathrm{kg} \mathrm{DMI}$ \\
\hline & Feed costs, dry period & $\$ 0.15 / \mathrm{kg}$ DMI \\
\hline & Price per $\mathrm{kg}$ of carcass weight & $\$ 1.52 / \mathrm{kg}$ \\
\hline & Risk-free discount rate & $5 \% / y r$ \\
\hline \multirow[t]{9}{*}{ Herd data } & Average herd milk production per year & $9072 \mathrm{~kg}$ \\
\hline & Weight at birth & $41 \mathrm{~kg}$ \\
\hline & Weight of an adult dairy cow & $612 \mathrm{~kg}$ \\
\hline & Voluntary waiting period after calving & $50 \mathrm{~d}$ \\
\hline & Estrus detection rate & $40 \%$ \\
\hline & Conception rate & $40 \%$ \\
\hline & Age at first calving & $26 \mathrm{mo}$ \\
\hline & Dressing percentages within and across lactations & See Table 3 \\
\hline & Lactation function (see Revenues section in text) & $\begin{array}{l}\text { Wood (1967), Delorenzo et } \\
\text { al. (1992), or Skidmore } \\
(1990)\end{array}$ \\
\hline
\end{tabular}

${ }^{1}$ For additional variables, see Tables 3,4 , and 5.

where

$$
\begin{aligned}
\mathrm{CDO}_{\mathrm{CI}}= & \text { costs per } \mathrm{DO}(\$), \\
\mathrm{CI}= & \mathrm{CI}(\mathrm{mo}), \\
\mathrm{RPO}_{\mathrm{CI}}= & \mathrm{RPO} \text { value in first month of a lactation } \\
& \text { with a CI measured in months, and } \\
\mathrm{RPO}_{\mathrm{CI}+1=} & \mathrm{RPO} \text { value in first month of a lactation } \\
& \text { with a CI of } \mathrm{CI}+1 \text { mo. }
\end{aligned}
$$

To calculate the effect of a difference in $\mathrm{CI}$ on the RPO values, the RPO values in the first month of lactation (between calving and the end of the voluntary waiting period) were used. One could also choose a later month during the lactation (as long as this month is before the month of conception of the shortest CI) to compare RPO values and calculate the costs per extra DO. To keep the model consistent for different CI, the first month of the lactation was chosen. To get more insight in the costs per extra DO both the costs with and without opportunity costs (of a replacement heifer) were calculated. The RPO values without opportunity costs represent a situation where the RPO value is equal to the total net present value of the current cow (representing a situation where no replacement is available), without confounding by voluntary replacement.

\section{Input}

General. The spreadsheet model (http://cahpwww.vet.upenn.edu/software/econcow.html) was developed using Excel 2002 with Visual Basic for Applications (Microsoft, Redmond, WA). The user can customize the model by changing all input parameters and variables to calculate results for specific herd situations. In the model, the performances, revenues, and costs of individual dairy cows were calculated for each month (30.4 d) to allow replacement at regular intervals within the lactation period. All future costs and revenues were discounted at a 5\% discount rate (Brealey and Myers, 2000). Previous work found that milk price, feed price, milk production, replacement costs, and carcass prices have the largest influence on optimal replacement decisions (Van Arendonk, 1985a). Therefore, to keep the number of input parameters low and the model simple, only these and a few other important parameters were included (Table 1). The default parameter values for this paper's application were chosen to represent a typical dairy farm in Pennsylvania.

Revenues. Three lactation curves are currently available in the model (the user chooses the curve with a pop-down menu), but other equations can easily be included. The lactation equation used in this paper's application was developed by Oltenacu et al. (1981), adapted by Marsh et al. (1988), and later modified by Skidmore (1990):

$$
\mathrm{Y}=\mathrm{A}(\mathrm{DIM})^{\mathrm{b}} \mathrm{e}^{\mathrm{c} \text { DIM }} \mathrm{e}^{\mathrm{gDP}}
$$

where 
Table 2. Input parameters used in the example calculations to generate the modified Oltenacu et al. (1981) lactation curve. (Structure and parameters of lactation curve can easily be changed by the user.)

\begin{tabular}{llll}
\hline Lactation no. & $\mathrm{a}$ & $\mathrm{b}$ & $\mathrm{c}$ \\
\hline 1 & -20 & 0.08 & -0.002 \\
2 & 14 & 0.12 & -0.004 \\
$>2$ & 14 & 0.16 & -0.005 \\
\hline
\end{tabular}

$$
\begin{aligned}
\mathrm{Y}= & \text { daily milk yield }(\mathrm{kg}), \\
\mathrm{A}= & ((\mathrm{GNRHA} / 100-\mathrm{a}) / 2.96), \\
\mathrm{GNRHA}= & \text { rolling lactation average (genetic rolling } \\
& \text { herd average }(\mathrm{kg} / \mathrm{yr}) \\
\mathrm{DIM}= & \text { days in lactation }(\text { milk }), \\
\mathrm{DP}= & \text { days in gestation (days pregnant) }, \\
\mathrm{e}= & \text { base of natural logarithm, and } \\
\mathrm{a}, \mathrm{b}, \mathrm{c}, \mathrm{g}= & \text { constants that determine the shape of the } \\
& \text { lactation curves. }
\end{aligned}
$$

For lactation numbers 1,2 , and $\geq 3$, different constants for the coefficients a, b, c, and g (Table 2) were used (Skidmore, 1990). The constant g, which determines the effect of gestation stage on milk yield, was modified to reflect a 200 - and $350-\mathrm{kg}$ cumulative milk yield decrease in the 305-d production of first and second and higher lactation animals (Olori et al., 1997). Prediction of future milk production levels was done, assuming a repeatability of 0.55 for the next lactation and 0.50 for all lactations afterward (mean reversion), similar to the method used by Van Arendonk (1985b). Whereas the current application of the model used this formula for generating lactation curves, in other situations other curves might be more applicable.

The average calf net revenues (bull or heifer calves) were estimated at $\$ 100$ and were added to the total revenues during the first month in each lactation. Monthly changes in carcass value were also included in the model. The carcass value was calculated from the following equation (Van Arendonk, 1985b):

$$
\mathrm{CV}_{\mathrm{i}, \mathrm{j}}=\mathrm{LW}_{\mathrm{i}} \mathrm{D} \%_{\mathrm{i}}\left(\mathrm{p}_{\mathrm{j}}+\mathrm{dp}_{\mathrm{i}}\right)
$$

where

$$
\begin{aligned}
\mathrm{CV}_{\mathrm{i}, \mathrm{j}}= & \text { carcass value of cow } \mathrm{i} \text { in month } \mathrm{j}, \\
\mathrm{LW}_{\mathrm{i}, \mathrm{j}}= & \text { live weight }(\mathrm{kg}) \text { of cow } \mathrm{i} \text { in month } \mathrm{j}, \\
\mathrm{D} \%_{\mathrm{j}}= & \text { dressing percentage }(\%) \text { in month } \mathrm{j}, \\
\mathrm{P}= & \text { average price per kilogram of carcass } \\
& \text { weight for a heifer } 210 \mathrm{~d} \text { in lactation }(\$ / \\
& \mathrm{kg}), \text { and } \\
\mathrm{dp}_{\mathrm{j}}= & \text { price in month } \mathrm{j} \text { as a deviation from the } \\
& \text { average } \mathrm{p}_{\mathrm{j}}(\$ / \mathrm{kg}) .
\end{aligned}
$$

The effect of lactation number and stage of lactation on dressing percentage and the price per kilogram of carcass weight is given in Table 3 . This price was expressed as a deviation from the price of a heifer at 7 mo in lactation, which was taken at $\$ 1.52 / \mathrm{kg}$ (Pennsylvanian Agricultural Statistic Service, 1997).

The live weight of each cow in each month of lactation was calculated from the function developed by Korver et al. (1985). This function takes into account age, DIM, number of days pregnant, mature weight, and birth weight. Furthermore, the maximum decrease of live weight during lactation was set at $50 \mathrm{~kg}$ at 75 DIM (Van Arendonk, 1985b). Finally, the effect of pregnancy on live weight was excluded, in agreement with Van Arendonk (1985b). Live weight was used in the model to calculate carcass value and to determine DMI.

Costs. In the model, the rearing of young stock was isolated from other activities under the assumption that pregnant heifers are purchased from the farm's rearing enterprise or through the market. The costs of replacement heifers for this paper's application were calculated by interpolation data from the Cornell Cattle System 4 model (Van Amburgh and Fox, 1996). These data imply that, between reasonable biological limits, the total costs per kilogram of weight gain are lower with a lower age at first calving. The total costs of a replacement heifer calving at an age of 26 mo were, therefore, calculated at $\$ 1132$, which was consistent with the average costs to raise a replacement heifer of $\$ 1124$ found by Gabler et al. (2000). However, the user can include costs of replacement animals at any price without using the interpolated data.

Feed costs were calculated by multiplying the DMI $(\mathrm{kg})$ of each individual cow with the costs per kilogram of DMI. The DMI was calculated using the following formulas (Galligan et al., 1985).

For lactating cows:

$$
\begin{aligned}
\mathrm{DMI}_{\mathrm{i}, \mathrm{j}}= & 1.10+0.015 \mathrm{BW}_{\mathrm{i}, \mathrm{j}}+0.2185 \mathrm{P}_{\mathrm{i}, \mathrm{j}} \\
& +0.0001280 \mathrm{BW}_{\mathrm{i}, \mathrm{j}} * \mathrm{P}_{\mathrm{i}, \mathrm{j}} ;
\end{aligned}
$$

For dry cows:

$$
\mathrm{DMI}_{\mathrm{i}, \mathrm{j}}=1.92+0.012 \mathrm{BW}_{\mathrm{i}, \mathrm{j}}
$$

where

$$
\begin{aligned}
\mathrm{DMI}_{\mathrm{i}, \mathrm{j}} & =\mathrm{DMI}(\mathrm{kg}) \text { for cow } \mathrm{i} \text { in month } \mathrm{j} \\
\mathrm{BW}_{\mathrm{i}, \mathrm{j}} & =\text { mature } \mathrm{BW}(\mathrm{kg}) \text { for cow } \mathrm{i} \text { in month } \mathrm{j}, \text { and } \\
\mathrm{P}_{\mathrm{i}, \mathrm{j}} & =\text { milk production }(\mathrm{kg}) \text { for cow } \mathrm{i} \text { in month } \mathrm{j} .
\end{aligned}
$$

Although this model can account for a variety of feeding systems, a one-group TMR was used in this paper's application. The costs of DMI in lactating cows were set at $\$ 0.20 / \mathrm{kg}$ (US $\$ 0.09 / \mathrm{lb}$ ). The feed costs for growing 
Table 3. Effect of lactation number and stage of lactation on the dressing percentage (D\%) and the deviation in price (/kg carcass weight).

\begin{tabular}{|c|c|c|c|c|c|c|c|c|c|c|c|c|}
\hline \multirow[b]{2}{*}{ Trait } & \multicolumn{12}{|c|}{ Lactation number at calving } \\
\hline & 1 & 2 & 3 & 4 & 5 & 6 & 7 & 8 & 9 & 10 & 11 & 12 \\
\hline & 50.0 & 49.8 & 49.6 & 49.4 & 49.3 & 49.2 & 49.1 & 49.0 & 48.9 & 48.7 & 48.5 & 48.2 \\
\hline \multirow[t]{2}{*}{ Price $^{1}(\$)$} & 0.00 & -0.01 & -0.014 & -0.02 & -0.03 & -0.04 & -0.05 & -0.06 & -0.08 & -0.1 & -0.12 & -0.14 \\
\hline & \multicolumn{12}{|c|}{ Month in lactation } \\
\hline Trait $^{2}$ & 1 & 2 & 3 & 4 & 5 & 6 & 7 & 8 & 9 & 10 & $>10$ & Dry period \\
\hline $\mathrm{D} \%$ & -0.6 & -0.6 & -0.6 & -0.6 & -0.4 & -0.2 & 0.0 & +0.2 & +0.4 & +0.6 & +0.6 & +0.2 \\
\hline Price $(\$)$ & -0.04 & -0.04 & -0.04 & -0.03 & -0.02 & -0.01 & 0.00 & 0.02 & 0.02 & 0.02 & 0.02 & +0.01 \\
\hline
\end{tabular}

${ }^{1} \mathrm{As}$ a deviation of the price for a heifer $210 \mathrm{~d}$ in lactation.

${ }^{2} \mathrm{As}$ a deviation of the value at $210 \mathrm{~d}$ in lactation within one lactation.

heifers and dry cows were $\$ 0.15 / \mathrm{kg}$ of DMI $(\$ 0.07 / \mathrm{lb})$ (Galligan et al., 1985).

To calculate the breeding costs for different CI, the estrus detection rate was set at $40 \%$, and the conception rate was set at $40 \%$, close to what has been observed in the field (Smith et al., 1988; Lucy, 2001). The voluntary waiting period was assumed to be $50 \mathrm{~d}$. The breeding costs per month were calculated by multiplying the expected number of breedings per month with the insemination costs per breeding. The expected number of breedings per months was calculated as the potential number of breedings per month (1.45, which was calculated as $30.4 \mathrm{~d} \div$ estrous cycle of $21 \mathrm{~d}$ ) multiplied by the estrus detection rate. The minimal number of total breedings per pregnancy was set at one.

Other costs included (Table 4) were the costs associated with morbidity, disposal, and mortality. Typically, yearly veterinarian costs per cow were estimated at $\$ 50$ for an average first lactation cow (Snow, 1993) and increased \$5 each lactation. Van Arendonk (1985b) assigned $33 \%$ of these costs to the first month, $11 \%$ to the second and third months, and 5\% to the later months of each lactation. The direct financial costs associated with mortality were set equal to the slaughter values.

Type of cow disposal not subject to this decision-making was referred to as involuntary culling (Van Arendonk, 1985b). Field data on culling probabilities are biased because of voluntary culling (Giaever, 1966; Dijkhuizen, 1983). Therefore, to obtain marginal probabilities on involuntary culling (Tables 4 and 5), Dijk- huizen (1983) corrected field data on culling probabilities within and across lactations for voluntary culling. Finally, the financial losses caused by idle production factors (lack of immediate replacement) were set equal to $\$ 50$ and were assigned to the month in lactation during which the cow had to be involuntarily disposed.

Application on dairy herds. The calculations of the RPO values of 5 dairy cows are shown to illustrate the way in which the model could be used on a dairy herd or by a researcher or government organization. The input values of the parameters that are needed to obtain the RPO values and, if the cow is not pregnant and replacement of is not the optimal decision, the costs per extra DO of each of these 5 cows are estimated. The cows were assumed to be part of a typical Pennsylvania herd, and, consequently, their economic optimal replacement was determined by comparing the cow's performance with that of an average heifer on such a herd (Table 1).

\section{RESULTS AND DISCUSSION}

\section{RPO Values}

The RPO value is an economic index that makes it possible to rank animals according to their future profitability; the higher the RPO, the more valuable the animal. An RPO value has 2 important and related meanings. First, any RPO value $<0$ means that immediate replacement is the most profitable choice; there is

Table 4. Average veterinary costs and mortality and disposal percentages of dairy cows per lactation.

\begin{tabular}{|c|c|c|c|c|c|c|c|c|c|c|c|c|}
\hline & \multicolumn{12}{|c|}{ Lactation number } \\
\hline & 1 & 2 & 3 & 4 & 5 & 6 & 7 & 8 & 9 & 10 & 11 & 12 \\
\hline Veterinary costs $(\$)$ & 50 & 55 & 60 & 65 & 70 & 75 & 80 & 85 & 90 & 95 & 100 & 105 \\
\hline Disposal & 0.14 & 0.15 & 0.18 & 0.20 & 0.23 & 0.25 & 0.27 & 0.29 & 0.32 & 0.35 & 0.38 & $0.41^{1}$ \\
\hline
\end{tabular}

${ }^{1}$ Because the maximum age is set at 12 lactations, the marginal disposal rate in the last month of lactation 12 is 1. 
Table 5. Allocation of the morbidity, mortality, and disposal in different months of the lactation as a proportion of the total in each lactation.

\begin{tabular}{|c|c|c|c|c|c|c|c|c|c|c|c|c|c|c|c|c|c|}
\hline & \multicolumn{17}{|c|}{ Month in lactation (12-mo calving interval) } \\
\hline & 1 & 2 & 3 & 4 & 5 & 6 & 7 & 8 & 9 & 10 & 11 & 12 & 13 & 14 & 15 & $16^{1}$ & $17^{1}$ \\
\hline Morbidity & 0.33 & 0.11 & 0.11 & 0.05 & 0.05 & 0.05 & 0.05 & 0.05 & 0.05 & 0.05 & 0.05 & 0.05 & 0.05 & 0.05 & 0.05 & 0.05 & 0.05 \\
\hline Mortality & 0.20 & 0.20 & 0.20 & 0.04 & 0.04 & 0.04 & 0.04 & 0.04 & 0.04 & 0.04 & 0.04 & 0.04 & 0.04 & 0.04 & 0.04 & 0.04 & 0.04 \\
\hline Disposal & 0.15 & 0.07 & 0.06 & 0.07 & 0.08 & 0.10 & 0.11 & 0.11 & 0.10 & 0.09 & 0.06 & 0.05 & 0.04 & 0.04 & 0.04 & 0.03 & 0.03 \\
\hline
\end{tabular}

${ }^{1} 16$ and 17 mo represent the rates in the dry period.

no extra profit to be expected from trying to keep the cow, compared with replacing her (Figure 1). Second, the RPO represents the cow's economic value beyond the slaughter value, i.e., the total maximum amount of money that could be spent in trying to keep an animal in case of reproductive failure or health problems (Van Arendonk, 1985a; Huirne et al., 1997).

For 5 different milk production levels, the calculated RPO values for typical Pennsylvania conditions are given in Table 6, calculated for cows that have just become pregnant at 6 mo after calving (resulting in a 15 -mo CI). The RPO values in Table 6 vary between $-\$ 37$ and $+\$ 1995$; variability was mainly caused by the difference in milk production. A first lactation cow with a relative milk production of $76 \%$ has an $\mathrm{RPO}$ value of -\$37, which means that keeping her 1 additional mo instead of replacing her with an average replacement heifer (if available) would cost the producer $\$ 37$. In contrast, if the producer would have to cull (involuntarily) a first lactation heifer that has a relative production level of $124 \%$ and replace her with an average heifer, he would have an economic loss of $\$ 1995$.

For cows with a 15-mo (average) CI and under the 5 different production levels (the same production characteristics as Table 5), the sequences of RPO values are shown in Figure 2. As can be seen from Figure 2, a cow's RPO value can be negative temporarily and become positive again because of the high future expected milk and calf revenues from a new lactation. When this cow with a negative RPO value is kept (instead of replaced) and she was successfully bred, her RPO can become positive again during the late stages of gestation. If this is the case, the producer should keep the cow until the RPO becomes negative again. To determine optimal breeding and replacement decisions, the sequences of RPO values are more useful. Figure 2 shows 4 main attributes of the sequences of the RPO values within and across lactations.

First, cows having a higher milk production have significantly higher RPO values for a given reproductive efficiency. A large influence of the cow's relative level of milk production on the average monthly net revenues during the lactation period has been previously reported (Van Arendonk, 1985a; Kristensen, 1993). Cows with a $124 \%$ milk production level with a 15-mo CI (herd average) have a maximum RPO value at the end of their first lactation (start of the second) of around US $\$ 1800$. Assuming a normal distribution with the average milk production of $9072 \mathrm{~kg}(20,000$ $\mathrm{lb})$ and a standard deviation of $907 \mathrm{~kg}(2500 \mathrm{lb})(\mathrm{De}$ Veer and Van Vleck, 1987), only $2.7 \%$ of the cows have a milk production $\geq 124 \%$. Finally, Houben (1995) found that not including within-lactation transitions results in an overestimation of high-producing cows and an underestimation of low-producing cows in the beginning of the lactation. As the current model allows for transitions between different levels of milk production only at the end of the lactation period, the model's effect of milk production on RPO could be slightly overestimated.

Second, the RPO value of a cow is generally the highest just before calving. For cows with a 15-mo CI, the $\mathrm{RPO}$ is minimal around 7 to 9 mo after calving, depending on the milk production level. Thereafter, the

Table 6. Retention pay-off of cows that became pregnant at 6 mo after calving (in $\$$ ).

\begin{tabular}{lrrrrr}
\hline & \multicolumn{5}{c}{ Relative production level of cow ${ }^{1}$} \\
\cline { 2 - 5 } Lactation & $76 \%$ & $88 \%$ & $100 \%$ & $112 \%$ & $124 \%$ \\
\hline 1 & $\$ 37$ & $\$ 224$ & $\$ 814$ & $\$ 1404$ & $\$ 1995$ \\
3 & $\$ 10$ & $\$ 226$ & $\$ 702$ & $\$ 1178$ & $\$ 1654$ \\
5 & $\$ 9$ & $\$ 139$ & $\$ 554$ & $\$ 970$ & $\$ 1385$ \\
7 & $\$ 8$ & $\$ 70$ & $\$ 431$ & $\$ 793$ & $\$ 1154$ \\
9 & $\$ 7$ & $\$ 28$ & $\$ 306$ & $\$ 599$ & $\$ 893$ \\
11 & $\$ 6$ & $\$ 27$ & $\$ 164$ & $\$ 345$ & $\$ 529$ \\
\hline
\end{tabular}

${ }^{1}$ Relative to the herd average milk yield (\%). 


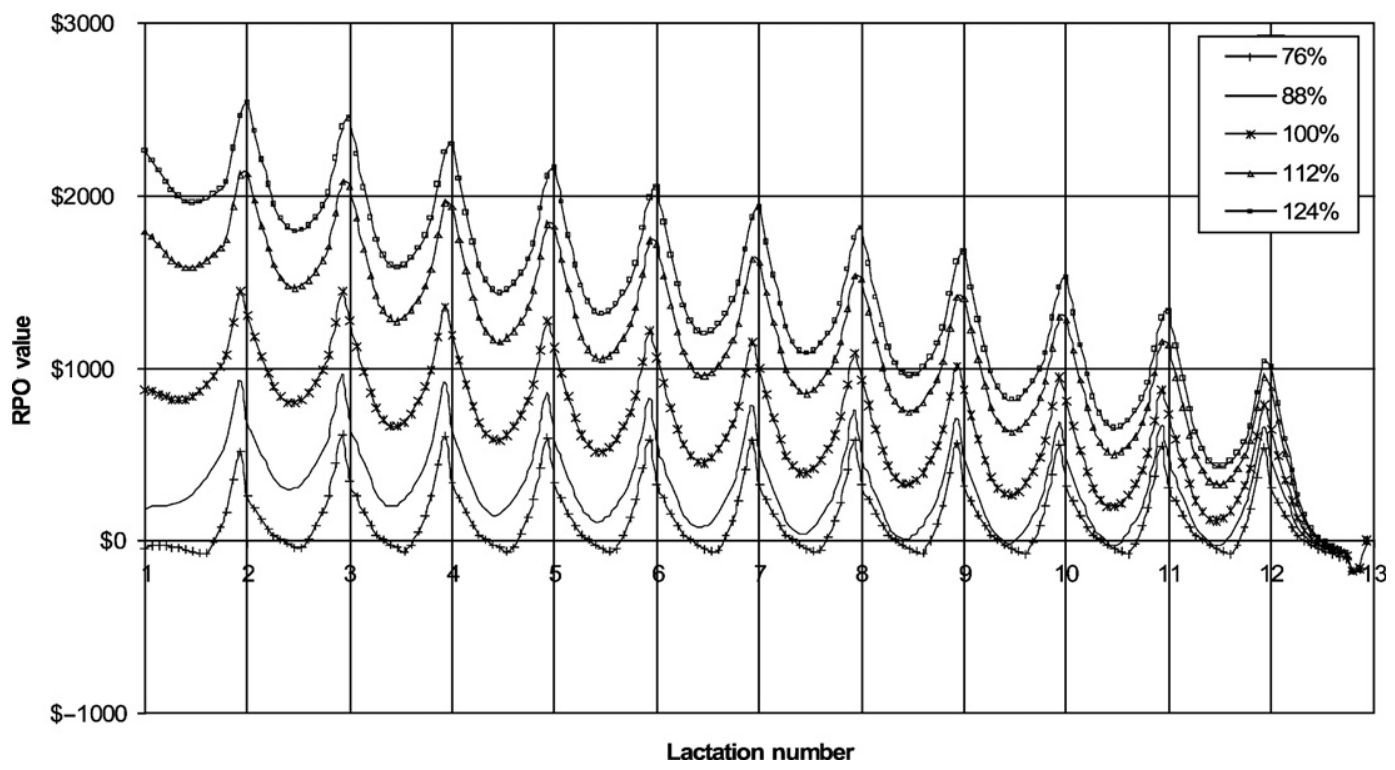

Figure 2. Retention pay-off (RPO) value for different milk production levels (relative to the herd average milk production) for cows with an average 15-mo calving interval. (Vertical lines indicate calving event; a successful breeding occurs 9 mo before.)

RPO increases again (Figure 2) because of the decreasing risk that she is involuntarily culled before calving, the increasing expected revenues of the next lactation, and because during the dry period the costs are becoming sunk cost.

Third, the maximum RPO values across lactations for high-producing cows gradually decline from lactation 1 to 12 . An exception is that for lower-than-averageproducing cows the maximum RPO values increase from lactation 1 to 2, but after lactation 2, the RPO values are also gradually decreased. The lower RPO value in the first lactation of low-producing animals was caused by the lower production in this lactation compared with later lactations (Equation 5). For average- and higher-than-average-producing cows, lower production in the first lactation was offset by the high relative production level of the cow $(\geq 100 \%)$ compared with an average replacement heifer. After reaching the maximum, the RPO value of cows gradually declines with a higher lactation number for 3 reasons. First, the time until optimal culling becomes shorter, and, therefore, the total extra profits of keeping the cow until this optimal time of replacement (= RPO value) decrease. The 2 other reasons for the decreasing RPO values are the higher involuntary culling and higher morbidity rates in later lactations.

Fourth, the RPO of cows with a lower production level decreased $<0$ around 6 to 7 mo in lactation, depending on lactation number and reproductive efficiency. For example, during the third lactation, under a 15-mo CI, the $\mathrm{RPO}$ value of a cow at $76 \%$ production goes $<0$ at
7 mo, which means that this cow should be replaced after 7 mo in milk. If the RPO value of a cow is negative, replacing her is economically more attractive than keeping her. However, if the producer decides to keep the cow and successfully breeds her, her RPO value will increase again $>0$ around 4 mo before calving. Beyond that point, the cow should be kept again until the next optimal time of replacement when the RPO again goes $<0$.

The calculations of the opportunity costs $\left(\mathrm{ANR}_{\max }\right.$; see Equation 1) were based on the average performance of animals present in the herd, assuming this to be the best estimates for future net revenue of young replacement animals. Three underlying assumptions of the results shown above are 1) no genetic gain, 2) unlimited availability of identical replacement heifers, and 3) constant number of cows in the herd. Genetic gain would result in lower RPO values because the opportunity costs are higher (i.e., replacement heifers are on average better than the current average animals). However, Van Arendonk (1985a) showed that genetic gain had only a very small influence on the optimal breeding and replacement decisions. Secondly, opportunity costs are 0 if there are (temporarily) no replacement heifers available. Replacements on dairy farms are often dictated by the calving of new heifers (Kristensen, 1993), and then naturally the least profitable cows should be replaced. Such situations often arise in herds that only use homegrown heifers, which is a very common policy in Pennsylvania. Opportunity costs can also be 0 (temporarily) when circumstances of the dairy farm allow 


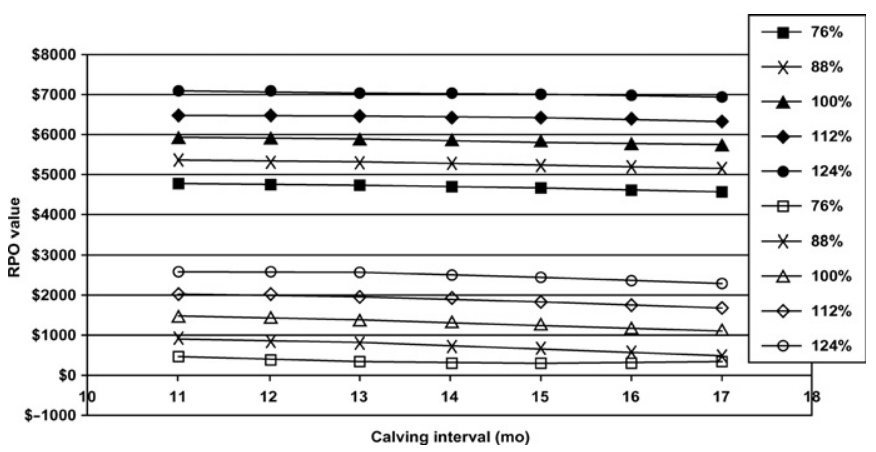

Figure 3. Retention pay-off (RPO) values if replacement heifers are available (bottom: with opportunity costs) and if replacement heifers are not available (top: without opportunity costs) for cows in the first month of the third lactation with 5 different milk production levels for different potential future calving intervals.

heifers to be added without requiring existing cows to be culled. This situation can occur because of planned long-term expansion or short-term fluctuation in cattle numbers (Lehenbauer and Oltjen, 1998). In both situations when opportunity costs are 0 , current cows can be kept as long as her MNR is $>0$ (Huirne et al., 1997). However, in any situation, the ranking of cows according to their RPO values selects the least profitable cow, and if a heifer is available, this cow is replaced (Kristensen, 1993). Therefore, the ranking of cows is more important than the absolute RPO values (Kristensen, 1993). In addition, the ranking of RPO values is far less sensitive to changing opportunity costs and changing prices and interest rates than the absolute RPO values.

\section{Costs per Extra DO}

The model calculated the RPO value of cows that have different reproductive efficiencies as measured by differences in their CI. First, Figure 3 shows the RPO values of cows in the first month of the third lactation without and with opportunity costs. A comparison of the situation with and without opportunity costs reveals 2 main differences. First, the RPO values without opportunity costs are considerably higher than the RPO values with opportunity costs. This is caused by 2 factors. First, the RPO values with opportunity costs represent the total extra profits of keeping the cow compared with replacement. Therefore, the opportunity costs (expected maximal average revenues of the replacement heifer) are subtracted from the MNR of the present cow (see Equation 2). In contrast, the RPO values without opportunity costs represent the extra profits of keeping the cow compared with an open place in the barn (zero opportunity costs subtracted). Second, the age until optimal replacement will be lower for situations where a

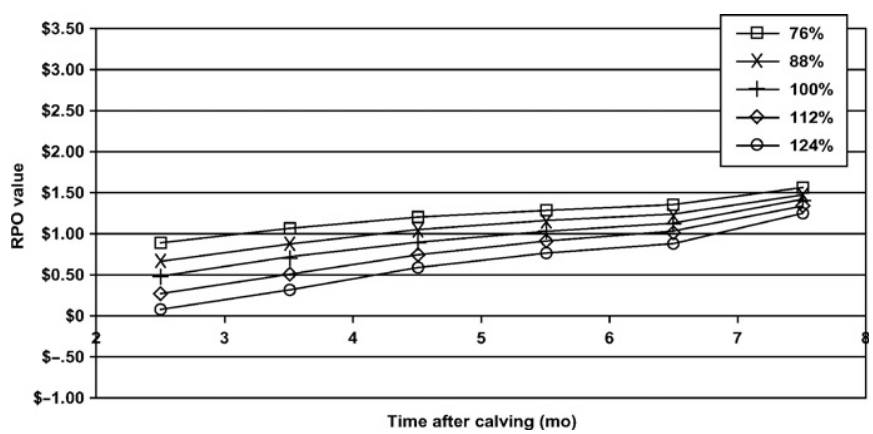

Figure 4. Costs per extra day open for third lactation cows with 5 production levels (no replacement heifers available and without opportunity costs).

replacement heifer is available than for situations where no replacement heifers are available. As a consequence, the total profits of keeping the cow were lower. The second difference between both situations is the slope. In the situation in which no opportunity costs were included, the graphs always had a negative slope (future value of the cow became lower); in the situation with opportunity costs, depending on the milk production, beyond a certain CI, the slope becomes zero. The reason is that if the $\mathrm{CI}$ increases, postponing breeding of the cow will not always decrease the RPO value of the cow because of the model's assumption of economical optimal culling. Because the model calculates the total benefits of keeping the current cow until the optimal time of replacement, it does not take into account losses that occur after this optimal time of replacement. As a consequence, a longer CI (beyond the maximum interval that is allowed to still be economically attractive) will not result in a decreased RPO in the model and subsequently will not result in losses per additional DO (in other words, the cow should not be bred at all).

For the same 2 situations (without and with opportunity costs), the costs per extra DO (set equal to the negative slope of the graphs) were calculated, which are shown in Figures 4 and 5. Figure 4 shows a steady, almost linear increase of the costs per extra DO, increasing from about $\$ 0.10$ to $\$ 1.60$ if the number of DO increases from 2 to 8 mo for different milk production levels in a situation without opportunity costs. It shows that, without opportunity costs, the costs per extra DO are slightly higher for lower production levels. This is because during the later stages of lactation, lowproducing cows will have a MNR that is lower than that of an average replacement heifer, and an increase of DO will, therefore, result in higher losses than for a high-producing cow. This is in agreement with Strandberg and Oltenacu (1989), who found that a longer CI for high-producing cows does not decrease profitability as much as for low-producing cows. 


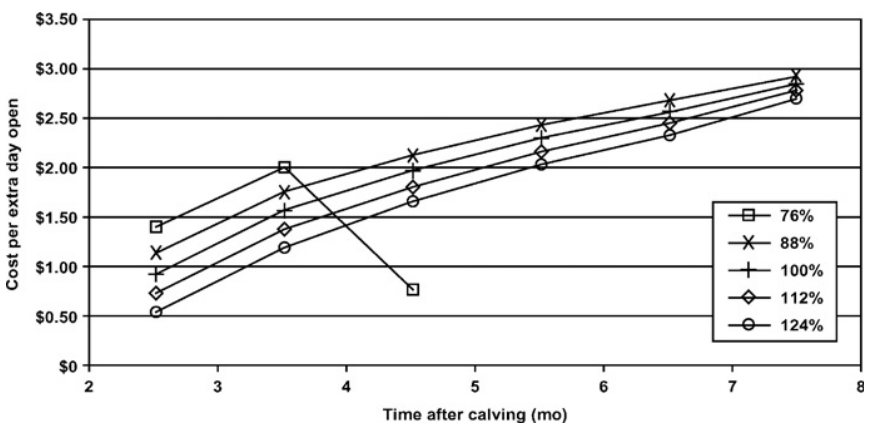

Figure 5. Costs per extra day open for third lactation cows with 5 production levels (with replacement heifers available and with opportunity costs).

Figure 5 shows the same trend, with costs per extra DO going up when the time after calving gets longer. Also, if a replacement heifer is available, the costs per extra DO are higher for lower-producing animals. However, there are 2 main differences between the situation where replacement heifers are available (Figure 5) or not (Figure 4). First, the costs per extra DO are considerably higher than in the situation where no replacement heifers are available. In other words, if a heifer can immediately take over the place of the cow, the costs of an extended CI increase substantially. A second difference is that Figure 5 shows a down-sloping line of the low-producing (76\%) cow. This represents the period during which a successful insemination will not increase the value of a cow anymore because replacement becomes economically the optimal decision. For a third lactation cow with a current relative milk production of $76 \%$, this occurs between 3 to 4 mo after calving.

Costs per extra DO vary across the lactation for animals in different lactations (first, second, and third) or with a low $(76 \%)$, average $(100 \%)$, or high $(124 \%)$ milk production levels (Figure 6). Costs per extra DO are lower and increase slower for first lactation animals than for animals in the second and higher lactation. This effect is caused by higher persistency of milk production of first lactation animals (Skidmore, 1990). Also, for all 3 lactations, the costs per extra DO are higher for low-producing animals than for higher producing animals. An exception to this, are animals (for example first lactation animals that produce $76 \%$ of the average) that should not be bred because breeding would not increase their RPO value and, therefore, is not optimal. Hence, the costs per DO will be calculated as $\$ 0$ (Equation 4 ) for these animals (Figure 6). Finally, the difference between an extra DO for average- and high-producing animals in the third lactation is small and smaller than the difference with first lactation ani-

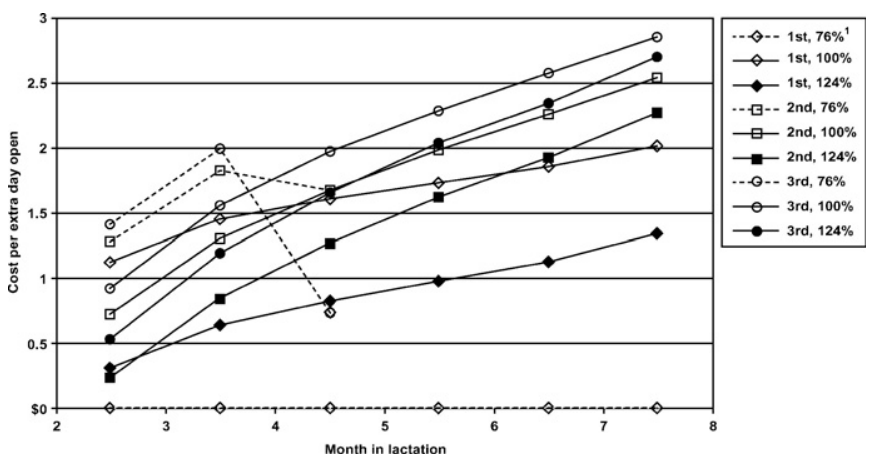

Figure 6. Costs per extra day open for first, second, and third lactation cows with a low (76\% level), average (100\% level), or high (124\% level) production level with replacement heifers available (with opportunity costs). ${ }^{1}$ Breeding does not increase the RPO value of first lactation cows at the $76 \%$ production level; hence, the costs per extra day open are shown as $\$ 0$.

mals (Figure 6). This result is in agreement with Dijkhuizen (1983), Van Arendonk (1985b), and Strandberg and Oltenacu (1989).

Costs of $\$ 2$ to $\$ 3$ per extra DO have often been quoted in studies dealing with the economic consequences of reproductive failure (Dijkhuizen, 1983; Strandberg and Oltenacu, 1989). Other studies suggested an advantage of a prolonged DO period for high-producing cows (Arbel et al., 2001). The results of the current model are in general agreement and show that the costs per extra DO vary greatly and are dependent on many factors. Four important factors are 1) availability of replacement heifers, 2) lactation number, 3) milk production level of both the cow and the herd mates, 4) and CI (used as a proxy for reproductive efficiency) of the cow. In the application of this model using typical input parameters for Pennsylvania, the costs per DO vary between $\$ 0$ and $\$ 3.00$ for a situation where replacement heifers are available. Therefore, fewer DO or shorter CI were economically optimal. If the number of DO extends beyond a certain maximum, replacement becomes economically the optimal decision, and breeding is not attractive anymore as illustrated at the $76 \%$ production level in Figure 5. In the model, economic costs per extra DO drop because pregnancy will not increase the economic value of the cow.

\section{Application on Dairy Herds}

The RPO values of 5 dairy cows are shown in Table 7. In addition to the herd data that are shown in Table 1 , the cow data that are needed to calculate individual RPO values include the cow's lactation number, the current milk production per day, the number of DIM, and the number of days pregnant. To determine the cow's milk production level as a percentage of the herd 
Table 7. Determination of the retention pay-off (RPO) values of 5 dairy cows in a typical dairy herd in Pennsylvania.

\begin{tabular}{|c|c|c|c|c|c|c|c|}
\hline \multicolumn{5}{|c|}{ Input parameter } & \multicolumn{3}{|c|}{ Output of the model } \\
\hline Cow & Lactation no. & Milk/d (kg) & DIM & Days pregnant & $\mathrm{ME}^{1}$ Milk (kg) & RPO value & Cost/extra $\mathrm{DO}^{2}$ \\
\hline 1 & 1 & 36 & 60 & 0 & 9124 & $\$ 419$ & $\$ 1.73 / \mathrm{d}$ \\
\hline 2 & 2 & 18 & 350 & 200 & 12,377 & $\$ 2015$ & $\mathrm{NA}^{3}$ \\
\hline 3 & 3 & 59 & 100 & 0 & 10,785 & $\$ 114$ & $\$ 2.24 / \mathrm{d}$ \\
\hline 4 & 5 & 36 & 140 & 60 & 7523 & $\$ 164$ & $\mathrm{NA}^{3}$ \\
\hline 5 & 10 & 29 & 210 & 0 & 7958 & $-\$ 7$ & $\mathrm{NA}^{4}$ \\
\hline
\end{tabular}

average mature equivalent milk, the inverse of the modified Oltenacu lactation curve (Equation 4; Oltenacu et al., 1981) was used. With these data, the model determines the individual RPO values and, if applicable, costs per additional DO.

The first cow (no. 1) was assumed to be 60 DIM with a milk production of $36 \mathrm{~kg} / \mathrm{d}$, which is very close to the average mature equivalent milk production of $9072 \mathrm{~kg}$ $(20,000 \mathrm{lb}) / \mathrm{yr}$ (Table 7$)$. The RPO value for her was $\$ 419$, but that value was projected to decrease by $\$ 1.73 /$ $\mathrm{d}$ as she stays open beyond $60 \mathrm{~d}$. However, costs per extra DO will increase gradually if the cow does not get bred as illustrated in general in Figure 5. The current milk production of the second cow was translated into a mature equivalent milk production of $12,377 \mathrm{~kg}$ $(27,286 \mathrm{lb})$, and a RPO value of $\$ 2015$. The costs per extra DO for Cow 3 are higher than for Cow 2 because she has been open for a longer time. Finally, the economical optimal decision for Cow 5 is to replace her (assuming an average replacement heifer is available), and breeding Cow 5 is not optimal; hence no costs of an extra DO were calculated.

\section{CONCLUSIONS}

Depending on lactation number, stage of lactation, reproductive status, and milk production level, the RPO value varied from $-\$ 181$ (for a cow that should be culled 'immediately') to $+\$ 2650$ (for a second lactation cow just before calving with a relative milk production level of $124 \%$ ). In addition to calculating RPO values to support replacement decisions, the current model provides a new perspective on the calculation of the costs per extra DO that takes into account the optimal breeding policy. With the current model, we found that the costs per extra DO vary between $\$ 0$ and $\$ 3$, depending on the cow and herd characteristics (Figures 4 to 6). In addition, the decision to breed a cow or not and the costs per extra DO were dependent on availability of replacement heifers.

With the current spreadsheet model, based on the MNR approach, the dairy cow breeding and replacement problem was modeled accurately, and optimal replacement and breeding decisions can be supported. The results are in close agreement with former studies (Van Arendonk, 1985a; Jalvingh, 1993; Kristensen, 1993; Houben, 1995). The strength of the currently described model is the integral evaluation of age, production, reproductive efficiency, and survivability in a simple and user-friendly economic computer spreadsheet model to support replacement and insemination decisions on dairy farms. Strandberg and Oltenacu (1989) concluded that there are no magic numbers for the optimal breeding and replacement decisions nor for the losses per marginal DO that apply to all herds and cows. Rather, there is a need of more customized breeding decisions for each (type of) cow that are herd specific. The current model can help in this need by providing user-friendly input and output to customize the calculations for individual herds and cows. On-farm, the model can support optimal decisions regarding voluntary replacement and breeding decisions. In addition, it can determine the on-farm costs associated with involuntarily culling or with additional DO. Other potential users of the current model are researchers, economists, and governmental organizations that wish to calculate the (farm or cow-specific) losses of involuntarily culled dairy cows because of a particular disease (Van Schaik et al., 1996) or as part of a specific disease control program (Groenendaal et al., 2002). Finally, users of the model can obtain estimates on the farm-specific costs of an extra DO for cows with different production characteristics, which can be useful to calculate the economics of specific insemination policies.

In summary, the current user-friendly model determines the economic value of individual dairy cows un- 
der farm-specific circumstances and uses a new approach to calculate the costs per extra DO. The results of the model are very similar to results of more complex models that are more difficult to use. Therefore, we consider the model a valuable tool for dairy farms to support farm and cow-specific optimal breeding and replacement decisions. Although not shown in this paper, the model can also be useful to assess economic costs of involuntary culling under disease control programs.

\section{REFERENCES}

Arbel, R., Y. Bigun, E. Ezra, H. Sturman, and D. Hojman. 2001. The effect of extended calving intervals in high lactating cows on milk production and profitability. J. Dairy Sci. 84:600-608.

Burt, O. R. 1965. Optimal replacement under risk. J. Farm Econ. 47:324-346.

Brealey, R. A., and S. C. Myers. 2000. Principles of Corporate Finance. 6th ed. McGraw-Hill, New York, NY.

Congleton, W. R., and L. W. King. 1984. Profitability of dairy cow herd life. J. Dairy Sci. 67:661-678.

DeLorenzo, M. A., T. H. Spreen, G. R. Bryan, D. K. Beede, and J. A. M. Van Arendonk. 1992. Optimizing model: Insemination, replacement, seasonal production, and cash flow. J. Dairy Sci. 75:885-896.

De Veer, J. C., and L. D. Van Vleck. 1987. Genetic parameters for first lactation milk yields at three levels of herd production. J. Dairy Sci. 70:1434.

Dijkhuizen, A. A. 1983. Economic aspects of disease and disease control in dairy cattle (in Dutch, with English summary). Ph.D. Thesis, Veterinary Faculty Utrecht, Utrecht, The Netherlands.

Gabler, M. T., P. R. Tozer, and A. J. Heinrichs. 2000. Development of a cost analysis spreadsheet for calculating the costs to raise a replacement dairy heifer. J. Dairy Sci. 83:1104-1109.

Galligan, D. T., J. D. Ferguson, C. F. Ramburg, and W. Chalupa. 1985. Dairy ration formulation and evaluation program for microcomputers. J. Dairy Sci. 69:1656-1664.

Giaever, H. B. 1966. Optimal dairy cow replacement policies. Ph.D. Diss., University of California, Berkeley.

Groenendaal, H., M. Nielen, A. W. Jalvingh, S. H. Horst, D. T. Galligan, and J. W. Hesselink. 2002. Johne's disease control: A simulation approach. Prev. Vet. Med. 54:225-245.

Houben, E. H. P. 1995. Economic optimization of decisions with respect to dairy cow health management. Ph.D. Diss., Wageningen Agricultural Univ., Wageningen, The Netherlands.

Huirne, R. B. M., A. A. Dijkhuizen, P. Van Beek, and J. A. Renkema. 1997. Dynamic programming to optimize treatment and replacement decisions. Pages 85-97 in Animal Health Economics; Principles and Applications. A. A. Dijkhuizen and R. S. Morris, ed. Post Graduate Foundation in Veterinary Science, University of Sydney, Sydney, Australia.

Jalvingh, A. W. 1993. Dynamic livestock modeling for on-farm decision support. Ph.D. Diss., Wageningen Agricultural Univ., Wageningen, The Netherlands.

Korver, S., J. A. M. Van Arendonk, and W. J. Koops. 1985. A function for live weight change between two calvings in dairy cattle. Anim. Prod. 40:233-241.
Kristensen, A. R. 1993. Markov decision programming techniques applied to the animal replacement problem. Ph.D. Diss., The Royal Veterinary and Agricultural University, Copenhagen, Denmark.

Lehenbauer, T. W., and J. W. Oltjen. 1998. Dairy cow culling strategies: Making economical culling decisions. J. Dairy Sci. 81:264-271.

Lucy, M. C. 2001. Reproductive loss in high producing dairy cattle: Where will it end? J. Dairy Sci. 84:1277-1293.

Marsh, W. E., D. T. Galligan, and W. Chalupa. 1988. Economics of recombinant bovine somatotropin use in individual dairy herds. J. Dairy Sci. 71:2944.

Morris, R. S., and W. E. Marsh. 1985. An economic assessment of control measures for bovine mastitis. IDF Seminar, Progress in Control of Bovine Mastitis. Kiel. Milch. Forschung. 37:244-252.

Oltenacu, P. A., T. R. Rounsaville, R. A. Milligan, and R. H. Foote. 1981. Systems analysis for designing reproductive management programs to increase production and profit in dairy herds. J. Dairy Sci. 64:2096-2104.

Olori, V. E., S. Brotherstone, W. G. Hill, and B. J. McGuirk. 1997. Effect of gestation stage on milk yield and composition in Holstein Friesian dairy cattle. Livest. Prod. Sci. 52:167-176.

Pennsylvanian Agricultural Statistics Service. 1997. Dairy Summary 1996. Harrisburg, PA.

Renkema, J. A., and J. Stelwagen. 1979. Economic evaluation of replacement rates in dairy herds. I. Reduction of replacements rates through improved health. Livest. Prod. Sci. 6:15.

Skidmore, A. L. 1990. Development of a simulation model to evaluate effectiveness of dairy herd management. Ph.D. Diss., Cornell University, Ithaca, NY.

Smith, B. J., J. F. Taylor, J. P. Walter, M. A. Tomaszewski, C. G. Woelfel, and D. J. Leatham. 1993. Seasonal effects on income over feed and replacement costs. J. Dairy Sci. 76:1678-1692.

Smith, R. D., P. A. Oltenacu, and H. N. Erb. 1988. The economics of improved reproductive performance. IRM-17. Dairy Integrated Reproductive Management. [Online]. Available at http:// www.wvu.edu/«exten/infores/pubs/livepoul/dirm17.pdf. Accessed September 4, 2003.

Snow, C. T. 1993. The Northeast Dairy Farm Summary. Farm Credit Bank of Springfield, PA.

Strandberg, E., and P. A. Oltenacu. 1989. Economic consequences of different calving intervals. Acta Agric. Scand. 39:407-420.

Van Amburgh, M. E., and D. G. Fox. 1996. Using the Cornell Model to predict nutrient requirements, performance, and costs for dairy heifers. Page 298 in Calves, Heifers, and Dairy Profitability: Proceeding from the Calves, Heifers, and Dairy Profitability National Conference, Harrisburg, PA. NRAES, Ithaca, NY.

Van Arendonk, J. A. M. 1985a. Studies on the replacement policies in dairy cattle. Ph.D. Diss., Wageningen Agricultural Univ., Wageningen, The Netherlands.

Van Arendonk, J. A. M. 1985b. A model to estimate the performance, revenues and costs of dairy cows under different production and price situations. Agric. Syst. 16:157-189.

Van Arendonk, J. A. M. 1988. Management guides for insemination and replacement decisions. J. Dairy Sci. 71:1050-1057.

Van Arendonk, J. A. M., and A. A. Dijkhuizen. 1985. Studies on the replacement policies in dairy cattle. III. Influence of variation in reproduction and production. Livest. Prod. Sci. 13:333-349.

Van Schaik, G., C. H. J. Kalis, G. Benedictus, A. A. Dijkhuizen, and R. B. M. Huirne. 1996. Cost-benefit analysis of vaccination against paratuberculosis in dairy cattle. The Vet. Rec. 139:624-627.

Wood, P. D. P. 1967. Algebraic model of the lactation curve in cattle. Nature 216:164-165. 